\title{
DESENVOLVIMENTO DE ÁRVORES NATIVAS EM ENSAIOS DE ESPÉCIES. 4. CASTANHA-DO-BRASIL (Bertholletia excelsa H. B. K.), DEZ ANOS APÓS O PLANTIO.
}

\author{
Noeli Paulo FERNANDES ${ }^{1}$; Jurandyr da Cruz ALENCAR ${ }^{1}$
}

\begin{abstract}
RESUMO - Três parcelas experimentais de Bertholletia excelsa (Castanha-do- Brasil) foram implantadas na Estação Experimental de Silvicultura Tropical do INPA/Manaus, em 1980, com o objetivo de obter dados sobre o crescimento da espécie com fins de produção de madeira e frutos. O sistema de plantio adotado foi em plena abertura, sobre Latossolo vermelho-amarelo, no espaçamento de $3.0 \times 3.0 \mathrm{~m}$. Foram observados, aos 10 anos, os seguintes resultados: diâmetro médio (DAP) de $13.9 \mathrm{~cm}$ e a altura total média de $15.41 \mathrm{~m}$; os valores máximos de diâmetros e alturas encontrados foram de $21.7 \mathrm{~cm}$ e $23,0 \mathrm{~m}$, respectivamente; a área basal média por hectare toi de $11.7098 \mathrm{~m}^{2}$, correspondendo a um volume médio de $117,291 \mathrm{~m}^{3} / \mathrm{ha}$; a espécie apresentou ótima desrama natural, boa adaptação ao Latossolo vermelho - amarelo, 69,44\% de sobrevivência média, boa forma de fuste, não tendo sido verificadas doenças ou pragas.
\end{abstract}

Palavras-chave: Castanha-do-Brasil. crescimento, plantio.

Development of Native Tree in Trial of Species 4. Castanha-do-Brasil. (Bertholletia excelsa H. B. K.), Ten Years After Planting.

ABSTRACT - Experimental plots of Berlholletia excelsa H. B. K. were implanted in 1980 at INPA's Experimental Station for Tropical Silviculture to study growth rates in terms of wood and nut production. The plantation was done on a clear-cutted area, with 3.0 by $3.0 \mathrm{~m}$ spacing. Ten years later we have observed the following averages: dbh $13.9 \mathrm{~cm}$ and total heigth 15.41 $\mathrm{m}$; maximum observed $\mathrm{dbh}$ and heigth were $21.7 \mathrm{~cm}$ and $23.0 \mathrm{~m}$, respectively: basal area average per hectare and mean volume per hectare were $11.7098 \mathrm{~m}^{2}$ and $117.291 \mathrm{~m}^{3}$; mean survival of $69.44 \%$; cylinder-shaped stem and complete absence of disease or pests. According to dbh average increment rate $(t \%)$ it was found a low increment at the age of six years, showing the necessity of thinning. not carryied out because it was just a case of growth trial plots. Up to now $B$. excelsa trees have showed very good natural pruning and adaptation for red-yellowish latossols.

Key-words: Brazilian nuts, growth, planting.

\section{INTRODUÇÃO}

\section{A Castanha-do-Brasil (Bertholletia} excelsa) é uma espécie que apresenta destaque na economia regional, em face da produção de castanha, de valor econômico nos mercados nacional e internacional.Em 1755, a castanha já era utilizada na alimentação e em 1918 passou a ser um importante produto de exportação do Estado do Pará (SOARES \& REALE, 1976). Até hoje, continua sendo exportada, principalmente para o mercado internacional.

Esta espécie fornece madeira de boa qualidade, mas o abate de árvores, nas florestas naturais na Amazônia, está proibido por lei, a fim de manter

1 Instituto Nacional de Pesquisas da Amazônia, Coordenação de Pesquisas em Silvicultura Tropical, Caixa Postal 478, 69011-970, Manaus, Amazonas, Brasil. 
os castanhais produtivos, que servem de sustentação e subsistência para as populações que vivem à base do extrativismo.

O presente trabalho apresenta resultados de crescimento em plantio a plena abertura, com fins de produção de madeira, incluindo informações gerais sobre a espécie.

\section{Informações gerais da espécie}

É espécie típica da floresta amazônica, ocorrendo naturalmente em florestas de terra-firme nos Estados do Pará, Maranhão, Amazonas, Acre, Rondônia e ao Norte de Mato Grosso. Ocorre ainda nas florestas limitrofes com o Suriname, Peru, Bolívia, Guiana Francesa e Venezuela (LOUREIRO et al., 1979).

Ocorre principalmente nas florestas de terra-firme, em solos argilosos. É muito abundante nas terras altas e nas "restingas altas" da Amazônia. Geralmente, é encontrada em grupos, formando os conhecidos "Castanhais".

Há problemas com os polinizadores especificos de $B$. excelsa em florestas e capoeiras (MULLER \& CALZAVARA, 1986), os quais estão passiveis de extinção em decorrência das queimadas que são feitas na região (KITAMURA \& MULLER, 1986).

Os agentes dispersores de sementes, como os roedores, também estão correndo risco de serem extintos pela caça indiscriminada, mas a maior ameaça à variabilidade genética é o próprio homem (LEITE et al., 1991). Estes autores propuseram locais para a conservação in situ desta espécie na
Reserva Florestal do Rio Negro e no Parque Nacional da Amazônia (região central) e também a instalação de Bancos Ativos de Germoplasma (BAG) e áreas de BAGs em várias partes da Amazônia, uma vez que somente a conservação in situ não resguarda contra a perda de variabilidade genética.

É árvore de grande porte, copa grande e emergente; fuste retilíneo, geralmente cilíndrico, com desrama natural de galhos em plantios, formando um eixo ortotrópico de excelente forma para a indústria.

A espécie floresce entre outubro a dezembro e o amadurecimento dos frutos ocorre 12 a 15 meses depois. A época de colheita vai de janeiro a março (estação chuvosa), estendendose por 6 meses. Cada árvore produz em média 100 a 150 litros de castanha (SOARES \& REALE, 1976).

A germinação da semente era um impecilho para a implantação de plantios desta espécie, uma vez que, quando não tratada, só germinava entre 1 a 1,5 anos, com aproximadamente $25 \%$ de germinação após a semeadura (PEREIRA et al.,1980 apud MULLER, 1981). A semeadura da amêndoa (sem casca) favoreceu a emergência docaulículo, 20 a 30 dias após a semeadura (MULLER \& FREIRE, 1979).

São disponiveis informações de crescimento em plantios experimentais em Curuá-una (SUDAM, 1979). avaliações de pequenos talhões existentes em Manaus, Macapá e Porto Velho (YARED et al., 1984) e resultados de 
crescimento em diâmetro, altura, volume e sobrevivência de várias procedências desta espécie, no Campo Experimental de Belterra, Pará (KANASHIRO \& YARED, 1988). As propriedades fisicas e mecânicas da madeira são encontradas em LOUREIRO et al. (1979).

\section{MATERIAL E MÉTODOS}

O plantio experimental foi instalado em 1980, na Estação Experimental de Silvicultura Tropical (EEST), no $\mathrm{km} 45$ da BR 174 (Manaus/Boa Vista). O solo da área, segundo RANZANI (1980), é considerado Latossolo vermelho-amarelo, de textura argilosa.

Foram implantadas 3 parcelas de $324 \mathrm{~m}^{2}$, com 36 plantas por parcela, no espaçamento de $3,0 \times 3,0$ metros, em plena-abertura.

O preparo da área consistiu na derrubada da vegetação, queima e encoivaramento. $\mathrm{O}$ plantio foi feito no mês de junho, transição para a estação seca, mas ainda com alta precipitação (188,8 mm), segundo CNPq/INPA (1980).

As mudas foram produzidas no viveiro da EEST, a partir de sementes oriundas de castanhais nativos, próximos a Belém. Estado do Pará. Fêz-se a primeira medição de altura total após o primeiro ano de plantio. As medições dos diâmetros à altura do peito (DAP) foram feitas após as árvores terem atingido alturas comerciais superiores a $1,30 \mathrm{~m}$ e a partir dai foram medidas anualmente.
A taxa de incremento do diâmetro médio foi calculada segundo a fórmula: $t \%=(D-d) /(D+d / 2) .100 ;$ onde $\mathrm{D}=$ diâmetro médio do período (ano) atual e $\mathrm{d}=$ diâmetro médio do período (ano) anterior. Considerou-se o diâmetro médio (DAP) das três parcelas (ARRUDA VEIGA, apud MANUAL DO TÉCNICO FLORESTAL, 1986). As fotos foram tiradas em novembro de 1990, quando o experimento estava com 10,5 anos.

\section{RESULTADOS E DISCUSSÃO}

As Figuras 1 e 2 mostram as formas dos fustes de $B$. excelsa aos 10,5 anos de idade, podendo-se observar uma desrama natural excelente, principalmente nas partes centrais das parcelas. $\mathrm{O}$ mesmo não aconteceu com as árvores das bordaduras, que receberam maior quantidade de luz (radiação) e tiveram desrama natural deficiente (Fig. 2). A maioria das árvores não desenvolveram galhos excessivamente grossos ou defeitos nos troncos.

$\mathrm{Na}$ Tabela 1 são apresentados os valores médios para as variáveis diâmetro (DAP), altura total, área basal média individual, área basal média/ha, os desvios padrões médios das variáveis diâmetro e altura total e o número médio de árvores vivas, determinados anualmente nas três parcelas. Na idade de 10 anos, a altura total média atingiu $15,41 \mathrm{~m}$ e o diâmetro médio $13,9 \mathrm{~cm}$, com desvios padrões de $4,63 \mathrm{~m}$ e $4,86 \mathrm{~cm}$, respectivamente. Nesta idade, a áreabasal média/ha foi de $11,7098 \mathrm{~m}^{2} / \mathrm{ha} \mathrm{e}$, 


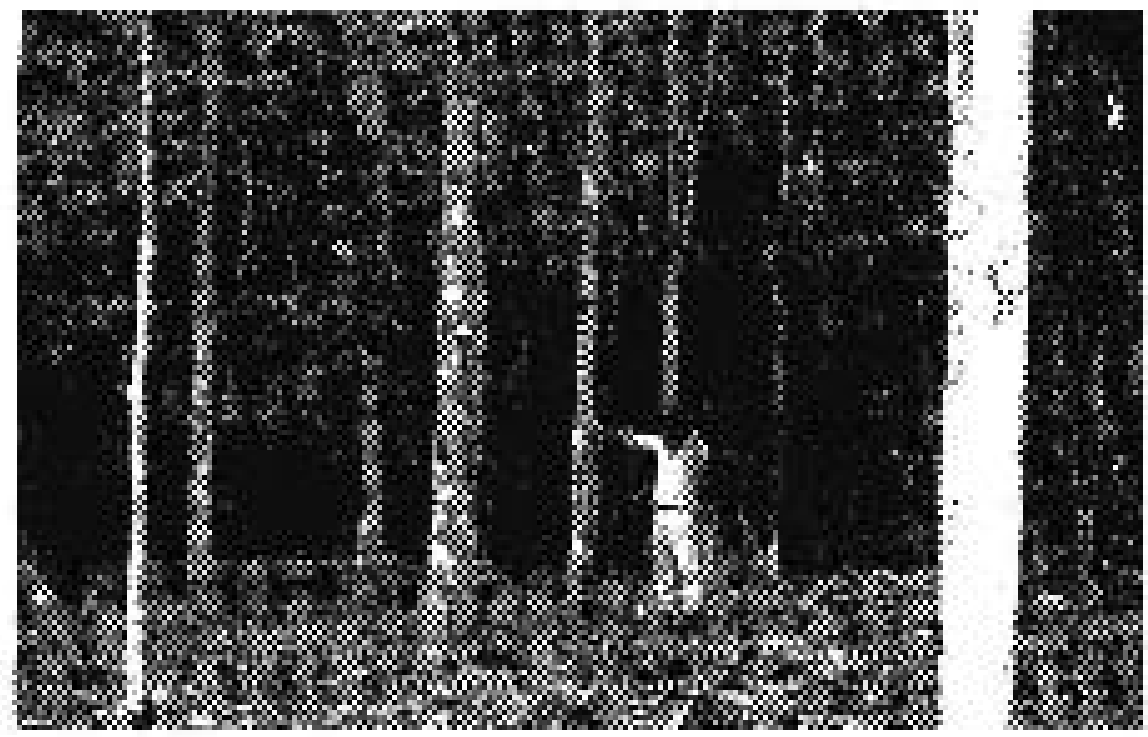

Figura 1. Aspectos dos fustes e da desrama natural de $B$. excelsa na parte mais sombreada da parcela (parte central). EEST/INPA. Manaus, AM.

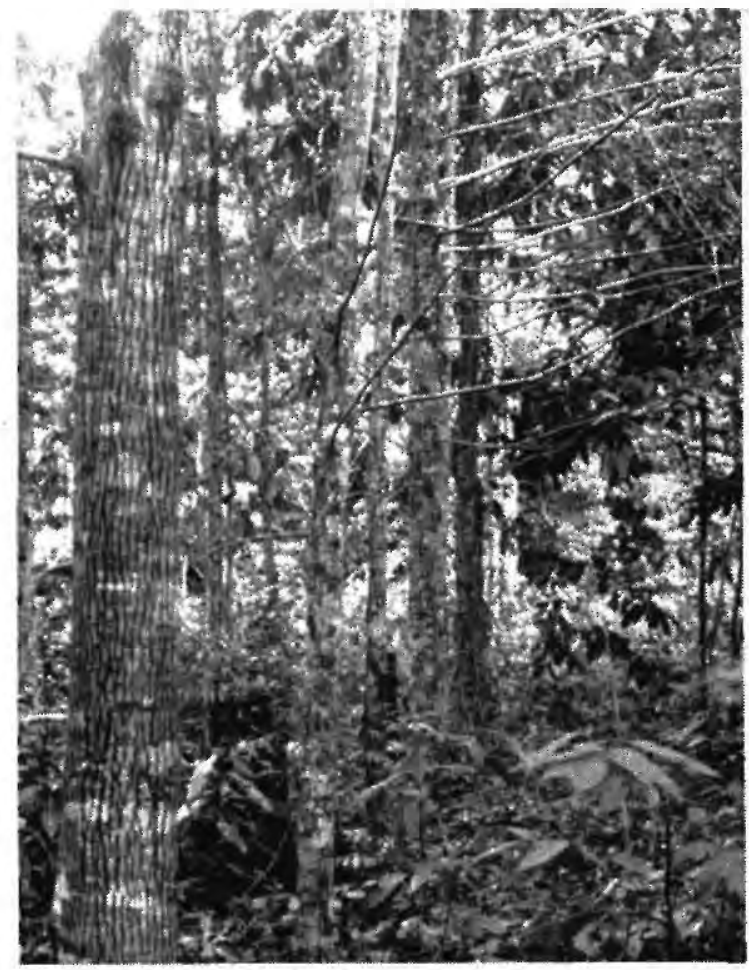

Figura 2. Desrama natural da linha de bordadura de $B$. excelsa, com ramos vivos (efeito de maior luminosidade). EEST/INPA. Manaus, AM. 
considerando-se um fator de forma de 0,65 , estimou-se um volume médio de $117,291 \mathrm{~m}^{3} /$ ha de madeira. A porcentagem de sobrevivência no plantio foi de $69,44 \%$, na idade de 10 anos. Dentre as procedências estudadas por KANASHIRO \& YARED (1988), no Estado do Pará e Rio Branco (Acre), eles relataram, para plantios com 5,5 anos de idade, que os melhores resultados foram obtidos com a Procedência Santarém - PA: Sobrevivência - $100 \%$; Altura - 7,5 m ; Diâmetro cm - 12,5 $\mathrm{cm}$; e Volume - 32,367 ( $\left.\mathrm{m}^{3} / \mathrm{ha}\right)$. Considerando os resultados da Tabela 1 , calculou-se nessa idade de 5,5 anos os seguintes valores médios: Sobrevivência - $83,33 \%$; Altura total $-6,5 \mathrm{~m}$; Diâmetro (DAP) - 8,65; Área basal média/ha - 5,50615; e Volume $23,442 \mathrm{~m}^{3} / \mathrm{ha}$, cujos valores são inferiores aos relatados por KANASHIRO \& YAREDO (1988), porém deve-se levar em consideração que eles utilizaram um espaçamento maior, de $4 \mathrm{~m} \times 4 \mathrm{~m}$.
Nas Figuras 3 e 4 são apresentadas as curvas de crescimento das variáveis altura total e diâmetro (DAP) e seus incrementos correntes anuais (ICA) e médios anuais (IMA), referentes aos valores médios das parcelas. Nos primeiros três anos, a espécie apresentou, para a altura total, valores irregulares de ICA, que teoricamente deveriam ser superiores aos valores de IMA, e uma redução próxima do $5^{\circ}$ ano. Entretanto, o ICA em altura continuou, como é normal, assumindo valores superiores ao IMA em altura, atingindo valor máximo na idade de 8 anos e valores iguais ao IMA próximos do $9^{\circ}$ ano (Fig. 3). Para a variável DAP, o ICA atingiu o ponto máximo na idade de 5 anos; a partir da idade de 6,5 anos observou-se uma redução dos incrementos correntes anuais e médios anuais, indicando saturação do crescimento (Fig. 4)

A taxa de incremento médio $(\mathrm{t} \%)$ do diâmetro médio mostrou

Tabela 1. Crescimento médio em altura total $(\mathrm{m})$, diânetro médio DAP (cm), área basal média individual $\left(\mathrm{m}^{2}\right)$, área basal média $\mathrm{m}^{2}$ ha e desvio padrão médio da altura total e DAP de $B$. excelsa EEST/INPA. Manaus. AM

\begin{tabular}{cccccccc}
\hline $\begin{array}{c}\text { Idade } \\
\text { (anos) }\end{array}$ & $\begin{array}{c}\text { DAP } \\
\text { médio } \\
(\mathrm{cm})\end{array}$ & $\begin{array}{c}\mathrm{s} \\
\text { total } \\
\text { média } \\
(\mathrm{m})\end{array}$ & $\begin{array}{c}\text { Altura } \\
\text { t }\end{array}$ & $\begin{array}{c}\text { Área basal } \\
\text { média } \\
\left(\mathrm{m}^{2}\right)\end{array}$ & $\begin{array}{c}\text { Área basal } \\
\text { media/ha } \\
\left(\mathrm{m}^{2}\right)\end{array}$ & $\begin{array}{c}\text { Nùmero } \\
\text { médio } \\
\text { arvores } \\
\text { vivas }\end{array}$ \\
\hline 1 & 0,8 & 0,28 & 1,22 & 0,43 & - & & 36 \\
2 & 2,5 & 0,87 & 2,09 & 0,66 & 0,0177 & 0,5463 & 36 \\
3 & 3,2 & 1,26 & 2,69 & 0,93 & 0,0265 & 0,8179 & 36 \\
4 & 4,4 & 1,99 & 4,70 & 1,71 & 0,0502 & 1,5494 & 33 \\
5 & 7,7 & 2,91 & 5,60 & 2,06 & 0,1397 & 4,3117 & 30 \\
6 & 9,6 & 3,36 & 7,51 & 3,07 & 0,2171 & 6,7006 & 30 \\
7 & 10,7 & 3,64 & 9,56 & 3,50 & 0,2428 & 7,4938 & 27 \\
8 & 12,9 & 4,60 & 14,10 & 4,30 & 0,3267 & 10,0833 & 25 \\
10 & 13,9 & 4,86 & 15,41 & 4,63 & 0,3794 & 11,7098 & 25 \\
\hline
\end{tabular}

$\mathrm{s}=$ Desvio padrāo 


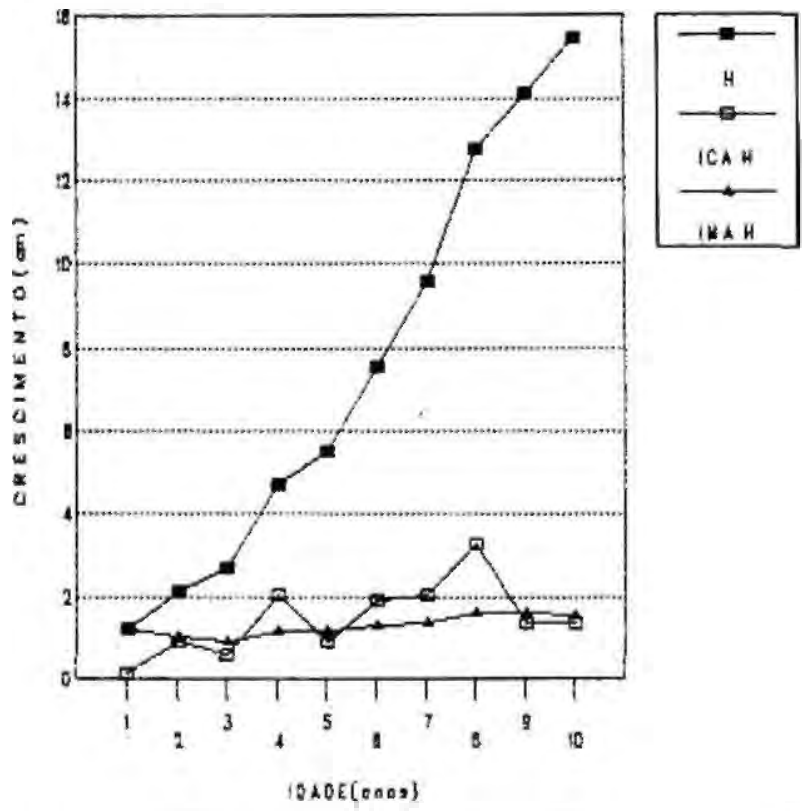

Figura 3. Crescimento médio em altura $(\mathrm{H})$, Incremento corrente anual (ICA) e Incremento médio anual (IMA) de B. excelsa. EST/INPA. Manaus - AM.

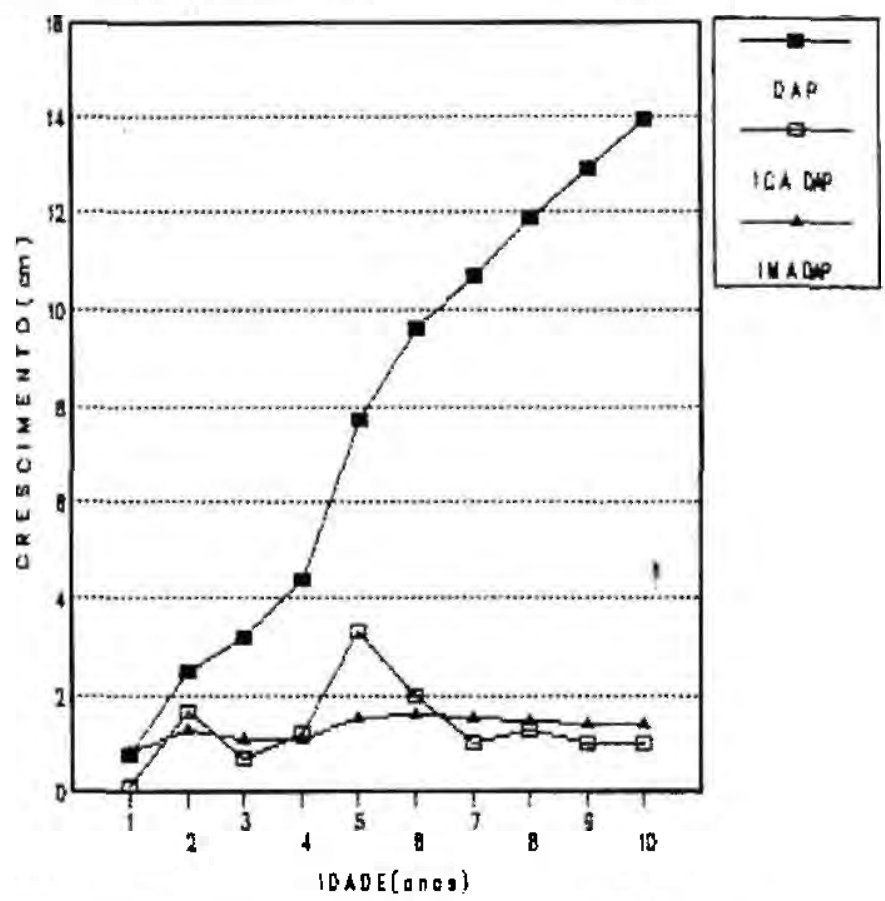

Figura 4. Crescimento médio ein diâmetro (DAP), Incremento corrente anual (ICA) e Incremento médio anual (MMA) de B. excelsa. EEST/INPA, Manaus, AM. 
também que a partir do $6^{\circ}$ ano houve redução do incremento para $30,05 \%$, atingindo na idade de 10 anos apenas $7,46 \%$ (Tab. 2). Portanto, a partir do $6^{\circ}$ ano ocorreu redução do crescimento diametral e a necessidade de realização de desbaste. Entretanto, por tratar-se de Parcelas Experimentais de Crescimento, não se executou desbaste, mas certamente seria feito no caso de plantios industriais. A tabela 2 mostra ainda os valores máximos das alturas totais e diâmetros encontrados para as árvores dominantes, em cada ano. $\mathrm{Na}$ idade de 10 anos a altura total máxima foi de $23,00 \mathrm{~m}$ e o diâmetro máximo atingiu $21,7 \mathrm{~cm}$. São valores relativamente superiores aos obtidos por YARED et al. (1984) em Manaus, Porto Velho e Macapá, onde, nas idades de 30 e 40 anos as médias de alturas totais foram de 20,0 a $24,0 \mathrm{~m}$. Nos experimentos de Curuá-Una, em plantios no espaçamento de $2,5 \times 2,4 \mathrm{~m}$, na idade de 17

Tabela 2. Taxa de incremento anual $(t \%)$ do diâmetro médio (DAP) e valores médios da altura total máxima e diâmetro máximo de B. excelsa. EEST/INPA. Manaus, AM.

\begin{tabular}{ccccc}
\hline $\begin{array}{c}\text { Idade } \\
\text { (anos) }\end{array}$ & $\begin{array}{c}\text { Diâmetro } \\
\text { médio DAP } \\
(\mathrm{cm})\end{array}$ & $\begin{array}{c}\text { t\% } \\
\text { Altura total } \\
\text { máxima } \\
(\mathrm{m})\end{array}$ & $\begin{array}{c}\text { Diâm. DAP } \\
\text { máximo } \\
(\mathrm{cm})\end{array}$ \\
\hline 1 & 0,8 & 50,00 & 2,10 & 1,5 \\
2 & 2,5 & 75,75 & 3,85 & 4,3 \\
3 & 3,2 & 42,10 & 4,90 & 6,0 \\
4 & 4,4 & 25,00 & 8,60 & 8,9 \\
5 & 7,7 & 37,19 & 10,50 & 13,8 \\
6 & 9,6 & 30,05 & 15,00 & 15,5 \\
7 & 10,7 & 14,78 & 16,80 & 17,2 \\
8 & 11,9 & 10,18 & 18,70 & 19,2 \\
9 & 12,9 & 8,87 & 20,30 & 20,3 \\
10 & 13,9 & 7,46 & 23,00 & 21,7 \\
\hline
\end{tabular}

anos, a espécie apresentou valores de altura máxima e mínima iguais a 21 e $12 \mathrm{~m}$, respectivamente.

\section{CONCLUSÕES}

- A espécie apresentou excelente crescimento em altura, diâmetro e área basal/ha, com ótima adaptação ao Latossolo vermelho-amarelo. - Não foram observados problemas de doenças e pragas, mostrando ser a Bertholletia excelsa indicada para plantios na região amazônica, com a finalidade de produção de madeira.

- A excelente desrama natural observada possibilita a obtenção de fustes de boa qualidade para a indústria.

- Na idade de seis anos ocorreu estagnação do incremento em diâmetro, indicando a necessidade de fazer-se desbaste, não executado por tratar-se de parcelas experimentais de crescimento. - Na idade de 10 anos a área basal média/ha foi de $11,7098 \mathrm{~m}^{2}$, correspondendo a um volume médio/ha de $117,291 \mathrm{~m}^{3}$ de madeira, e sobrevivência média de $69,44 \%$.

Recomendam-se que nos plantios industriais sejam feitos ensaios de desbaste, adubação e procedência, visando o aumento da produção.

\section{Bibliografia Citada}

CNPq/INPA 1980. Boletim Meteorológico. Janeiro a Julho de 1980.

KANASHIRO, M. \& YARED, J. A. G. 1988. Determinação da variabilidade genética populacional de Bertholletia excelsa e 
Didymopanax morototoni. Relatorio Técnico Anual do Centro de Pesquisa Agropecuária do Trópico Úmido. EMBRAPA/ CPATU. Belém:134-137.

KITAMURA, P. C.; MULLER, C. H. 1986. A depredação dos castanhais nativos na região de Marabá. In: Anais do Primeiro Simpósio do Trópico Úmido. EMBRAPA/DDT. Brasília. V. 6:277285.

LEITE, A. M. C.; SALOMÃO, A. N.; LLERAS, E. 1991. Areas prioritárias para conservação de cinco espécies florestais na floresta tropical úmida. EMBRAPA/CENARGEN. 26 p.

LOUREIRO, A. A; SILVA, M. F; ALENCAR, J. C. 1979. Essências Madeireiras da Amazônia. INPA, VI:121-125.

MANUAL DO TÉCNICO FLORESTAL. 1986. Apostilhas do Colégio Florestal de Irati. Campo Largo, Ingra S.A.. V.1:204-206.

MULLER, C. H. 1981. Castanha-do-Brasil Estudos Agronômicos.Embrapa CPATU, Belém. Documentos, 1: 25 p.
MULlER, C. H.; CALZAVARA, B. B. G. 1986. Castanha-do-Brasil: Conhecimentos Atuais. In:Primeiro Simpósio do Trópico Úmido. EMBRAPA/DDT. Brasilia. V. 4:223-29.

MUlleR, C. H.; FREIRE, C. O. 1979. Influência de fungicidas na conservação e na germinação de amêndoas de Castanha-do-Brasil EMBRAPA/CPATU. Belém. Comunicado Técnico. 9 p.

RANZANI, G. 1980. Identificação e caracterização de alguns solos da Estação Experimental de Silvicultura Tropical do INPA. Acta Amazonica, I0 (1):7-41.

SOARES, L. P; Reale, V. B. 1976. Castanhado-Brasil. Levantamento preliminar. Ministério da Agricultura. DEMA-Pará e FAEPA: 69 p.

SUDAM. 1979. Caracteristicas silviculturais de espécies nativas e exóticas dos plantios do Centro de Tecnologia da Madeira - Estação Experimental de Curuá-L/na. Belém. 351 p.

YARED, J. A. G.; MARQUES, L. C. T. CANASHIRO, M. 1984. EMBRAPA CPATU. Belèm. Relatório Anual, p 275-278. 